\title{
The ammonia sensitivity of Pt/GaAs Schottky barrier diodes
}

L. M. Lechuga, A. Calle, D. Golmayo, and F. Briones

Centro Nacional de Microelectrónica (CSIC), Serrano, 144-28006 Madrid, Spain

(Received 11 March 1991; accepted for publication 14 June 1991)

In this work a new ammonia gas sensor is presented. Schottky barrier devices, $\mathrm{Pt} / n-\mathrm{GaAs}$, with discontinuous platinum films are sensitive detectors of ammonia gas in a wide temperature range (from room temperature to $150^{\circ} \mathrm{C}$ ). The effect of parameters such as operation temperature, thickness of the catalytic metal film, background atmosphere, and applied voltage bias on the device sensitivity are investigated. In addition, significant characteristics have been examined including sensitivity limits, linearity of response, and adsorption and desorption kinetics.

\section{INTRODUCTION}

The determination of ammonia gas concentration is important in clinical, industrial process analysis, and environmental protection. For these reasons, it is useful to fabricate an ammonia sensor of small size, low cost, and high sensitivity.

Ammonia-sensitive structures based on metal-oxidesemiconductor (MOS) and metal-oxide-semiconductor field-effect transistor (MOSFET) devices with thin catalytic metal films have been reported. ${ }^{1-3}$ Two models have been proposed to explain the $\mathrm{NH}_{3}$ sensitivity of the thin catalytic gate device. It was first proposed that $\mathrm{NH}_{3}$ dissociated to yield atomic hydrogen, which diffuses to the metal-oxide interface to give a dipole layer. This changes the electrical characteristics of the device in a similar way as for hydrogen sensors. ${ }^{4}$ Later, Lundström and co-workers developed a model to explain $\mathrm{NH}_{3}$ sensitivity based on a capacitive coupling of ammonia molecules and/or reaction intermediates with the semiconductor through pores in the metal film. ${ }^{5}$

Schottky barrier devices have been shown to be excellent $\mathrm{H}_{2}$ gas sensors ${ }^{6,7}$ with high sensitivity and a behavior similar to MOS or MOSFET $\mathrm{H}_{2}$ gas sensors. ${ }^{8-10}$ In this work we present a new ammonia gas sensor based on a $\mathrm{Pt} / n$-GaAs Schottky barrier diode. The sensitivity of the sensor is given by the increase in capacitance observed when the $\mathbf{N H}_{3}$ gas reaches the structure. The change in capacitance is, therefore, a measurement of the amount of ammonia molecules in the ambient. We have carried out reaction kinetics studies via capacitance-time measurements as a function of temperature and $\mathrm{NH}_{3}$ concentration in different background atmospheres.

\section{EXPERIMENT}

The diodes were fabricated on (100) Si-doped GaAs epilayers (donor concentration, $N_{d}=4 \times 10^{15} \mathrm{~cm}^{-3}$ ), grown by molecular-beam epitaxy on a GaAs substrate. The devices have a dual metallic configuration: a thick (500-Å) Pt circular dot (diameter $=1 \mathrm{~mm}$ ) for an electric contact is first deposited. A thin porous Pt film (25-200 $\AA$ thickness) is evaporated over and outside the contact dot. $\mathrm{Pt}$ was electron-beam evaporated in an ultrahigh vacuum system at $10^{-7}$ Torr through a mask. Back ohmic contact on the $n$-type $\mathrm{GaAs}$ substrate is made previously by Au-Ge thermal evaporation with a subsequent annealing in $\mathrm{H}_{2}$ at $450^{\circ} \mathrm{C}$ for $30 \mathrm{~s}$. A quartz-crystal oscillator was used to estimate the thickness of the metal film. The diodes fabricated had an ideality factor close to unity. A schematic cross section of a $\mathbf{N H}_{3}$ sensor can be seen in Fig. 1.

Devices were located in a stainless-steel reaction chamber connected to a gas-flow panel which controlled the ambient atmosphere. Measurements were carried out in different gas mixtures: $\mathrm{NH}_{3}$ in $\mathrm{N}_{2}$ and $\mathrm{NH}_{3}$ in synthetic air $\left(20 \% \mathrm{O}_{2}\right.$ in $\mathrm{N}_{2}$ ); high-purity gases were used (moisture $\leqslant 5 \mathrm{ppm}$ ). All of the measurements were made at atmospheric pressure.

Gas-induced modifications in Schottky diode electrical properties are quantified by measuring changes in the diode capacitance as a function of time, as shown in Fig. 2. We have examined the effects of several parameters like temperature, voltage bias, and gaseous ambient. High-frequency $(1-\mathrm{MHz})$ capacitance-voltage $(C-V)$ and capacitance-time $(C-t)$ measurements were obtained with a Hewlett-Packard 4280A capacitance meter.

\section{RESULTS AND DISCUSSION}

\section{A. Influence of different parameters}

\section{Metal thickness, voltage bias, and temperature}

The metal microstructure strongly affects the $\mathrm{NH}_{3}$ sensitivity of sensors based on MOSFET devices ${ }^{2}$ with thin catalytic metal gates. We have studied a platinum film thickness range between 25 and $200 \AA$. . The devices did not show any sensitivity when the film was thicker than $150 \AA$, as shown in Fig. 3(a). In Fig. 3(b) we present measurements carried out in diodes with a platinum thickness of 25 and $75 \AA$, at $150^{\circ} \mathrm{C}$, and zero-voltage bias, in the presence of 75-300 ppm of ammonia. Normalized signals are used to compare the response of different diodes. The lack of ammonia sensitivity when the film becomes continuous indicates that the $\mathrm{NH}_{3}$ detection mechanism is different from the $\mathrm{H}_{2}$ detection mechanism.

The porous structure of the film has been observed by scanning electron microscopy (SEM) and scanning tunneling microscopy (STM). SEM and STM microphotographs show that the metal film has pores, although the film is electrically continuous. 


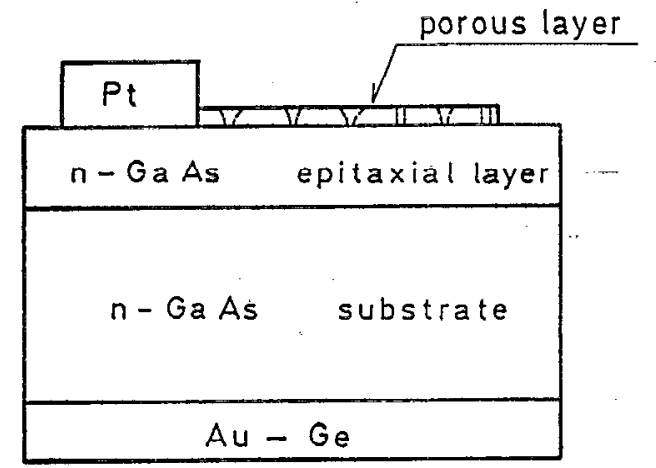

FIG. 1. Schematic cross section of an ammonia sensor. Pt dot thickness is $500 \AA$. Porous layer thickness is between 25 and $75 \AA$.

Figure 4(a) shows capacitance change for $970 \mathrm{ppm}$ of ammonia in nitrogen gas, at $150^{\circ} \mathrm{C}$, as a function of time for several bias voltages. Zero-voltage bias gives the largest signal. Furthermore, total recovery of the signal is achieved at this voltage for $150^{\circ} \mathrm{C}$. Consequently, we have made the forthcoming measurements at zero-voltage bias.

Figure 4(b) shows how the sensitivity increases with temperature for $970 \mathrm{ppm}$ of $\mathrm{NH}_{3}$ gas in nitrogen. The devices show a small but measurable response to $\mathrm{NH}_{3}$ even at room temperature, both in $\mathrm{N}_{2}$ and synthetic air.

\section{Background atmospheres}

The role of different carrier gases has been studied. Measurements were carried out at $150^{\circ} \mathrm{C}$ and zero-voltage bias. In all cases desorption was carried out in $\mathrm{O}_{2} / \mathrm{N}_{2}$ (50\%) at $150^{\circ} \mathrm{C}$ to achieve a complete desorption in about $2.5 \mathrm{~min}$. The total desorption process in synthetic air $\left(\mathrm{O}_{2} / \mathrm{N}_{2}\right.$ at $\left.20 \%\right)$ takes about $5 \mathrm{~min}$.

a. $\mathrm{NH}_{3} / \mathrm{N}_{2}$. The response to $\mathrm{NH}_{3}$ in $\mathrm{N}_{2}$ was investigated with an ammonia concentration from 40 to $970 \mathrm{ppm}$.

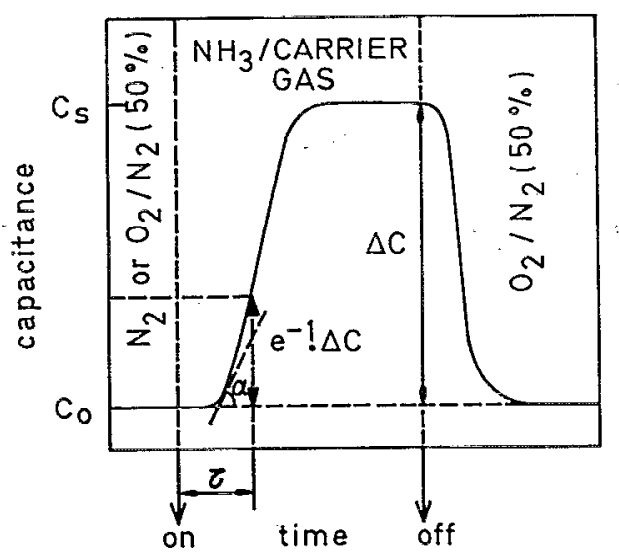

FIG. 2. Typical response curve (capacitance vs time) of a $\mathrm{NH}_{3}$ sensor. $\left(C_{0}\right)$ initial capacitance; $(\Delta C)$ increase of capacitance, measured just before desorption; constant time $(\tau)$, time in which the capacitance reaches the value $\left(e^{-1} \Delta C+C_{0}\right) ;(\Delta C / \Delta t=\tan \alpha)$ initial rate of adsorption (or desorption).
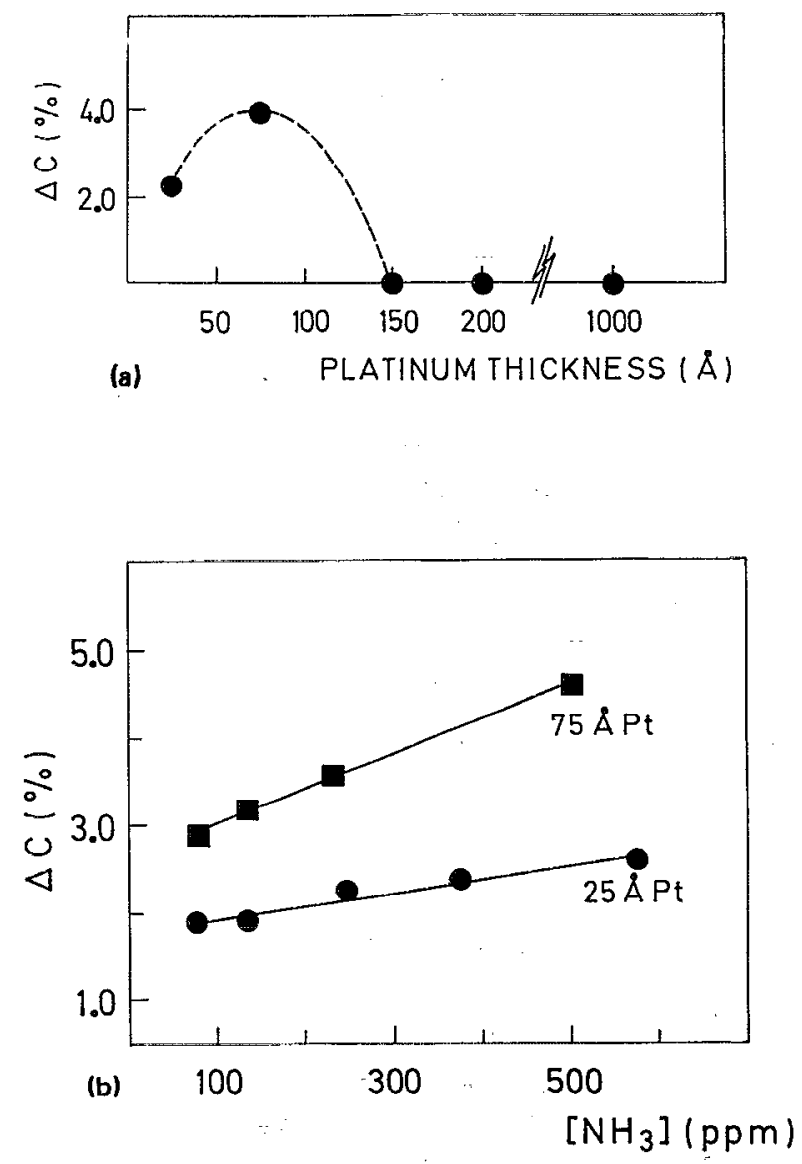

FIG. 3. (a) Dependence of the $\mathrm{NH}_{3}$ sensitivity with the porous $\mathrm{Pt}$ layer thickness. Signal is measured as normalized capacitance. Measurements were carried out for $225 \mathrm{ppm} \mathrm{NH}_{3}$ in $\mathrm{N}_{2}$ at $150^{\circ} \mathrm{C}$ and zero-voltage bias. (b) Sensitivity of the device as a function of $\mathrm{NH}_{3}$ partial pressure with thickness as a parameter: (๑) $25-\AA$ Pt film thickness, (四 $75-\AA \mathrm{Pt}$ film thickness.

The signal amplitude $(\Delta C)$ had the same value, although differences in time response were observed.

In the first set of measurements, the devices were previously exposed to a pure $\mathrm{N}_{2}$ atmosphere for 5-10 min before the introduction of $\mathrm{NH}_{3}$ gas. The response curve depicted in Figs. 5(a) and 5(b) shows some features depending on the ammonia partial pressure range. At high concentration the signal goes down abruptly when $\mathrm{NH}_{3} / \mathrm{N}_{2}$ is introduced, and then rises to give the adsorption curve. The values of initial capacitance depend on the previous exposure time to $\mathrm{N}_{2}$ gas. At low concentrations, Fig. 5(b), two regions are observed that are more evident for lower $\mathrm{NH}_{3}$ concentrations.

In the second set of measurements, experiments were carried out in an initial $\mathrm{O}_{2} / \mathrm{N}_{2}(50 \%)$ atmosphere prior to introduction of $\mathrm{NH}_{3} / \mathrm{N}_{2}$. Figure 6 presents the response curve. In this case, two regions are observed again for almost all of the ammonia partial pressure range. As the ammonia concentration decreases, the first signal increases, although the total signal is constant.

The first signal observed in Figs. 5(b) and 6 could be due to nitrogen gas adsorption. $\mathbf{N}_{2}$ gas replace the sites occupied by oxygen. It is known that certain ambient gases 

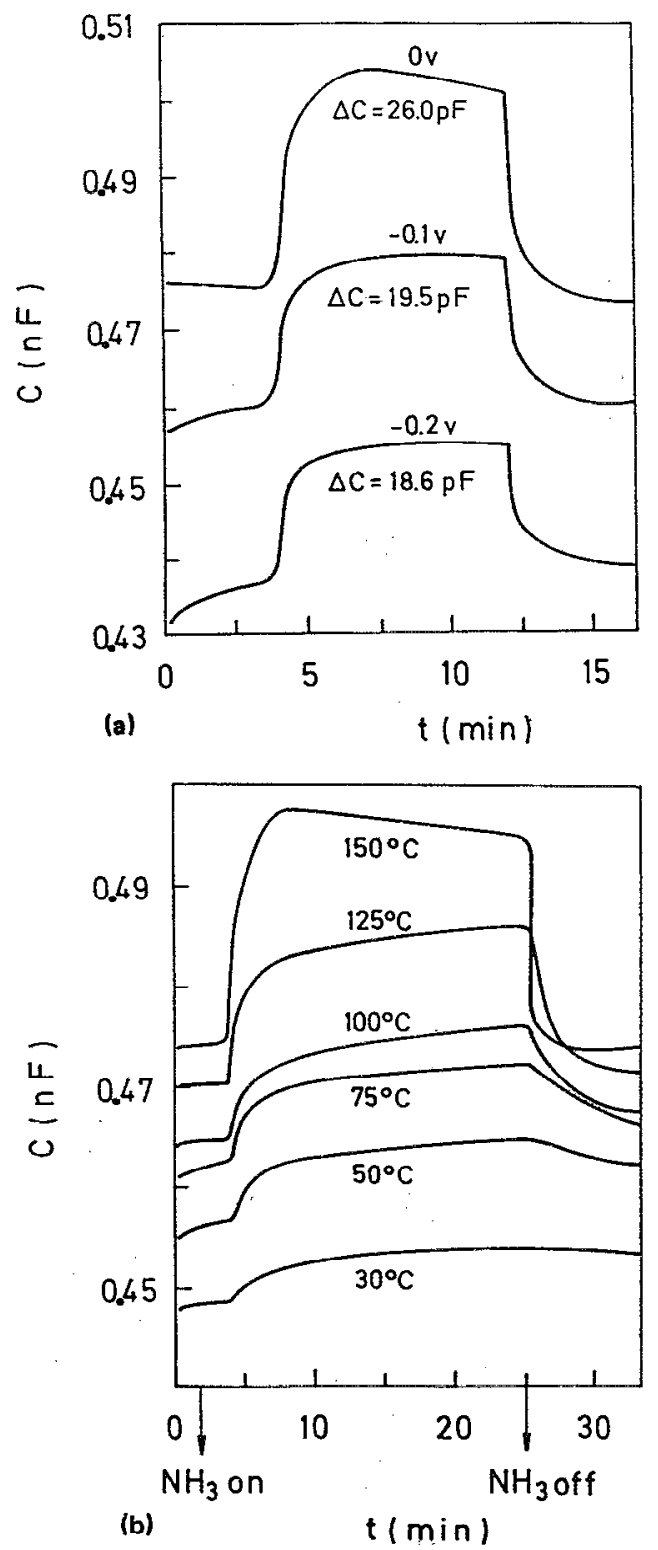

FIG. 4. Response curve of adsorption of $970 \mathrm{ppm} \mathrm{NH}_{3}$ in $\mathrm{N}_{2}$ : (a) voltage bias as a parameter at $150^{\circ} \mathrm{C}$, (b) temperature as a parameter at $0 \mathrm{~V}$.

can affect electrical properties of thin metal film ${ }^{11}$ and the heterogeneous catalytic activity of $\mathrm{Pt}$ in $\mathrm{N}_{2}$ adsorption ${ }^{12}$ has been established. In order to elucidate whether $\mathrm{N}_{2}$ gas originates the observed adsorption, we carried out adsorption studies of $\mathrm{N}_{2}$ gas, $\mathrm{NH}_{3}$ in $\mathrm{N}_{2}$, and $\mathrm{H}_{2}$ in $\mathrm{N}_{2}$. Figure 7 shows the adsorption curves at $150^{\circ} \mathrm{C}$ and zero-voltage bias. Pure $\mathrm{N}_{2}$ gas induced an adsorption curve which correlates in position and shape with the first adsorption observed in the response curves of $\mathrm{H}_{2} / \mathrm{N}_{2}$ and $\mathrm{NH}_{3} / \mathrm{N}_{2}$. The first adsorption signal corresponding to the curves of $\mathrm{NH}_{3} / \mathrm{N}_{2}$ and $\mathrm{H}_{2} / \mathrm{N}_{2}$ is very similar to the nitrogen adsorption signal $(\Delta C=9.0,9.5$, and $11.0 \mathrm{pF}$, respectively). Notice the high sensitivity for $\mathrm{H}_{2}$ in this type of device ( $\Delta C=9.7$ for $\mathrm{NH}_{3}$ and $128 \mathrm{pF}$ for $\mathrm{H}_{2}$, measured just before desorption), for the same gas concentration, and a similar response time.

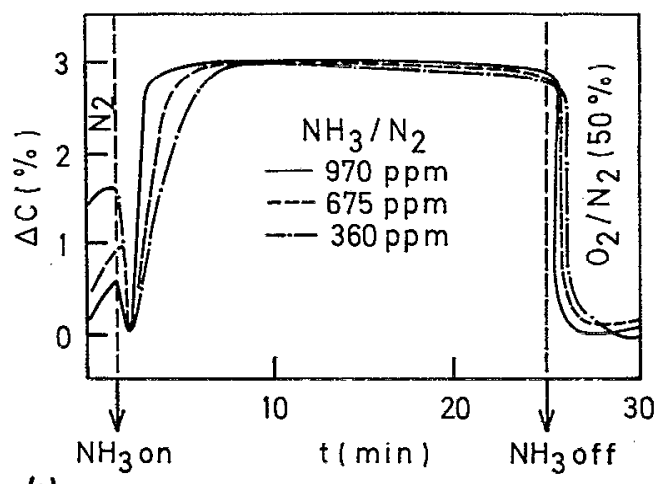

(a)

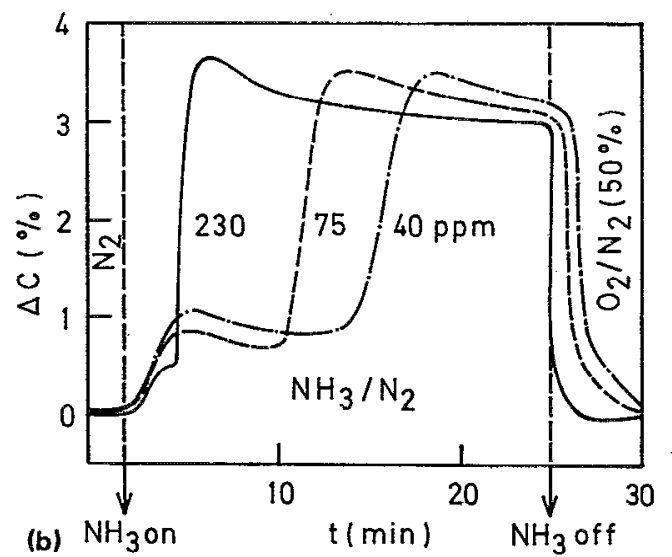

FIG. 5. Response curves of $\mathrm{NH}_{3}$ in $\mathrm{N}_{2}$, with a previous ambient of $\mathrm{N}_{2}$. Measurements were carried out at $150^{\circ} \mathrm{C}$ and zero-voltage bias. (a) $\mathrm{NH}_{3}$ concentration ranging between 970 and $360 \mathrm{ppm}$, (b) $\mathrm{NH}_{3}$ concentration ranging between 230 and $40 \mathrm{ppm}$.

Adsorption of $\mathrm{NH}_{3} / \mathrm{N}_{2}$ and $\mathrm{N}_{2}$ gas have been studied by means of $C-V$ measurements. Plots of $1 / C^{2}$ versus reverse voltage indicate that the Schottky barrier decreases when the gases are incorporated to the structure.

Plots of $1 / C^{2}$ versus reverse voltage for the different atmospheres are shown in the Fig. 8. Comparing to the air

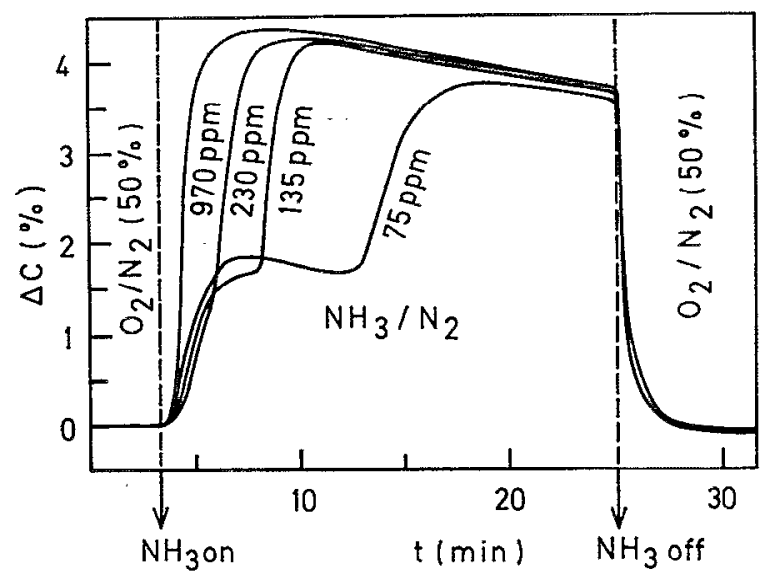

FIG. 6. Response curve of $\mathrm{NH}_{3}$ in $\mathrm{N}_{2}$ with a previous ambient of $\mathrm{O}_{2}$ in $\mathrm{N}_{2}$ (50\%). $\mathrm{NH}_{3}$ concentration ranges between 970 and $75 \mathrm{ppm}$. Measurements were carried out at $150^{\circ} \mathrm{C}$ and zero-voltage bias. 


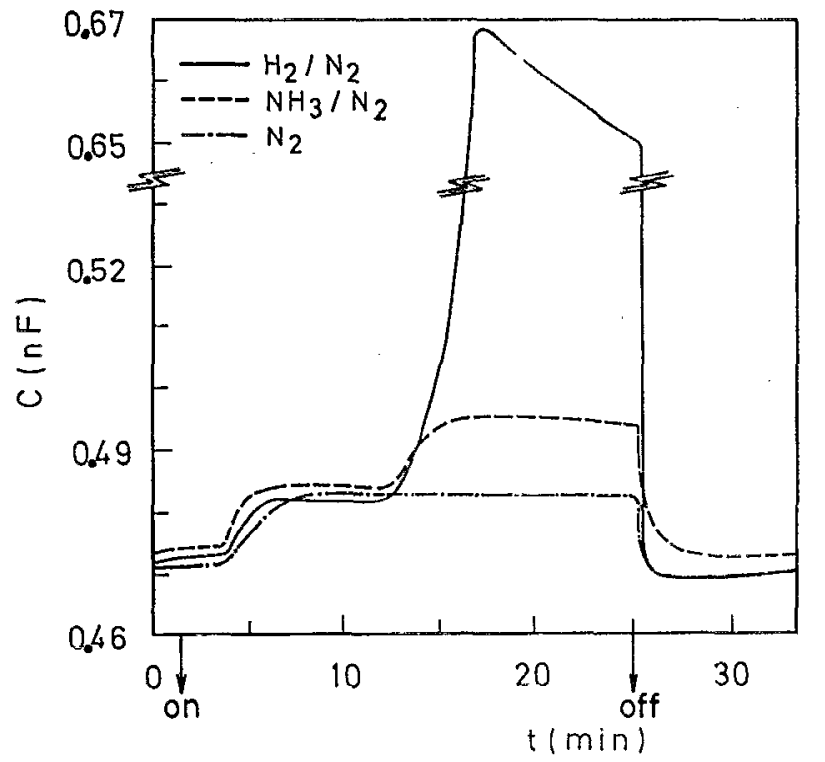

FIG. 7. Response curves for the adsorption of $75 \mathrm{ppm}$ of $\mathrm{NH}_{3}$ in $\mathrm{N}_{2}$ and $75 \mathrm{ppm}$ of $\mathrm{H}_{2}$ in $\mathrm{N}_{2}$ and $\mathrm{N}_{2}$ gas. Measurements were performed at $150^{\circ} \mathrm{C}$ and zero-voltage bias.

value [plot (a)], we obtain a Schottky barrier decreases of about $0.29 \mathrm{eV}$ for $970 \mathrm{ppm}$ of $\mathrm{NH}_{3}$ in $\mathrm{N}_{2}$ [plot (b)]. When $75 \mathrm{ppm}$ of $\mathrm{NH}_{3}$ in $\mathrm{N}_{2}$ are introduced in the reaction chamber, we have calculated two different values corresponding to the two processes observed, the first process giving a lowering of about $0.07 \mathrm{eV}$ [plot (c)], and the value corresponding to the second process is $0.20 \mathrm{eV}$ (plot is not shown). Furthermore, when pure $\mathrm{N}_{2}$ is introduced, we obtaincd a lowering of the Schottky barrier of $0.07 \mathrm{eV}$ [plot (d)]. This result corroborates the idea that the first region is the adsorption signal corresponds to $\mathrm{N}_{2}$ adsorption.

It is important to notice that, at temperatures below $75^{\circ} \mathrm{C}$, the $\mathrm{N}_{2}$ signal was not observed. At high tempera-

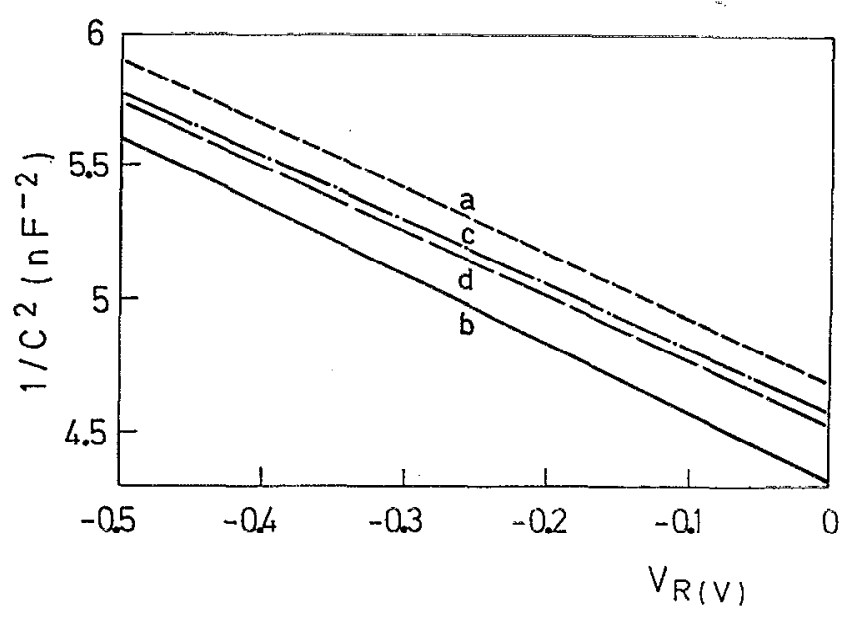

FIG. 8. $1 / C^{\alpha}$ vs reverse voltage for an ammonia sensor. (a) Sensor in synthetic air as a reference level. (b) Plot corresponding to the adsorption of $970 \mathrm{ppm}$ of $\mathrm{NH}_{3}$ in $\mathrm{N}_{2}$. (c) Plot corresponding to the first region observed in the adsorption curve of $75 \mathrm{ppm}$ of $\mathrm{NH}_{3}$ in $\mathrm{N}_{2}$. (d) Plot corresponding to $\mathrm{N}_{2}$ gas adsorption.
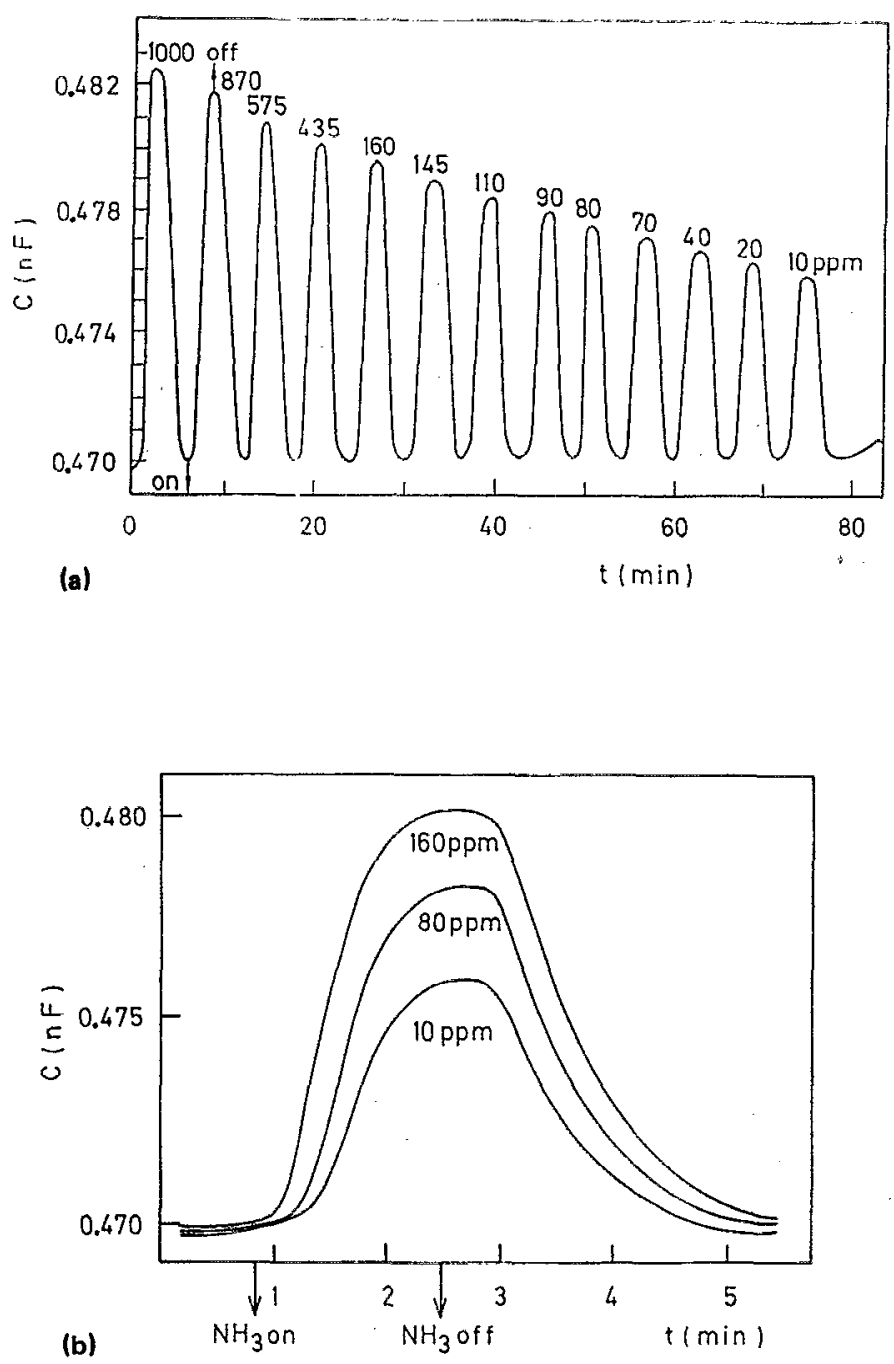

FIG. 9. (a) Response curves of $\mathrm{NH}_{3}$ diluted in synthetic air, measured at $150^{\circ} \mathrm{C}$ and zero-voltage bias. $\mathrm{NH}_{3}$ concentration varies between 1000 and $10 \mathrm{ppm}$. $\mathrm{ON}=$ introduction of $\mathrm{NH}_{3}$. OFF $=$ removal of $\mathrm{NH}_{3}$ and introduction of $\mathrm{O}_{2} / \mathrm{N}_{2}(50 \%)$. Time between pulses is 250 s. (b) Response curves of adsorption of $\mathrm{NH}_{3}$ in synthetic air corresponding to $\mathrm{NH}_{3}$ pulses of 160,80 , and $10 \mathrm{ppm}$.

tures, nitrogen behaves as an interference for the $\mathrm{NH}_{3}$ adsorption, although it is possible to differentiate both signals.

b. $\mathrm{NH}_{3}$ /air. The sensor was tested for ammonia in a synthetic air background atmosphere at $150^{\circ} \mathrm{C}$ and zerovoltage bias. Pulses of $\mathrm{NH}_{3}$ /air over a concentration ranging from 6 to $1200 \mathrm{ppm}$ were injected into the reaction chamber with $250 \mathrm{~s}$ between pulses to ensure a total recovery of the sensor (purge time is $33 \mathrm{~s}$ ). Figure 9 (a) shows the on/off response curve of the device. In this case the $\mathrm{N}_{2}$ adsorption process discussed above is not observed. Examples of the pulse responses are shown in Fig. 9(b). Such curves were recorded with a long time to evaluate the response time when the ammonia concentration decreases.

It is well known that the $\mathrm{H}_{2}$ gas-sensitive devices show an abrupt lowering of response when oxygen is present. ${ }^{7,8}$ However, $\mathrm{NH}_{3}$ sensitivity remains almost constant for different background atmospheres, $\mathrm{NH}_{3}$ in $\mathrm{N}_{2}$ or $\mathrm{NH}_{3}$ in syn- 


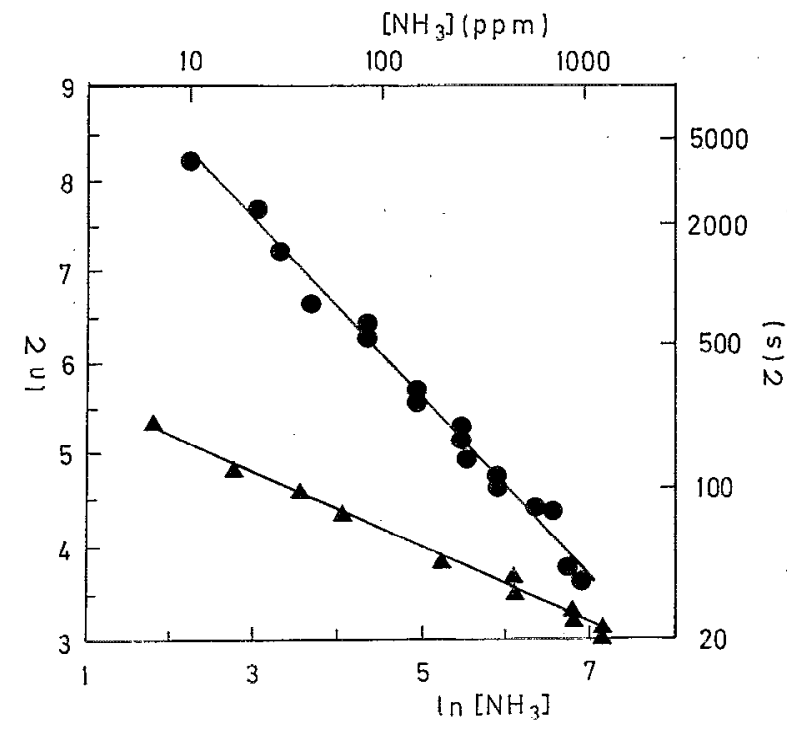

FIG. 10. Calibration graphs (constant time as a function of $\mathrm{NH}_{3}$ concentration) of a device at different background atmosphere: (1) $\mathrm{N}_{2},(\mathbf{A})$ synthetic air. Measurements were made at $150^{\circ} \mathrm{C}$ and zero-voltage bias.

thetic air. Therefore, the oxygen dependence of the ammonia response is different, and different rate-limiting reactions occur on the $\mathrm{Pt}$ surface for hydrogen and $\mathrm{NH}_{3}$ exposure.

We have observed that the adsorption signal varies for the range of $\mathrm{NH}_{3}$ partial pressures studied but this variation is small (only $7 \mathrm{pF}$ for concentrations ranging between 1000 and $10 \mathrm{ppm})$. However, the time required for the signal to appear varies with the concentration of $\mathrm{NH}_{3}$, as can be seen in Fig. 9(b). The time needed for the capacitance change to reach $e^{-1}$ of its final value was taken to be the time constant of the process (see Fig. 2). Figure 10 shows calibration plots of the time constant $(\tau)$ as a function of ammonia concentration for different background atmospheres. The calibration plots show the evaluation of $\mathrm{NH}_{3}$ adsorption in $\mathrm{N}_{2}$ (Fig. 6) and in synthetic air (Fig. 9). Time constants for $\mathrm{NH}_{3}$ in $\mathrm{N}_{2}$ have been evaluated with the initial value of capacitance referred to in the $\mathrm{N}_{2}$ saturation level. As can be seen in Fig. 10, the time constant of the device is lower in air than in $\mathrm{N}_{2}$ ambient in the whole range of $\mathrm{NH}_{3}$ partial pressures studied. However, the slope of the $\mathrm{NH}_{3} / \mathrm{N}_{2}$ calibration plot is larger than that for the $\mathrm{NH}_{3}$ /air ambient, therefore, it is possible to better differentiate between close ammonia concentrations. In both cases, the calibration graphs are linear in the whole range of $\mathrm{NH}_{3}$ concentrations studied in our experimental setup. The detection limit in $\mathrm{N}_{2}$ is $10 \mathrm{ppm}$ and decreases to $6 \mathrm{ppm}$ in synthetic air.

As observed in Fig. 10, the response time is less than 1 min for $\mathrm{NH}_{3}$ concentrations in air greater than $150 \mathrm{ppm}$. However, in $\mathrm{N}_{2}$ ambient similar response times are obtained only when the $\mathrm{NH}_{3}$ concentration is above $600 \mathrm{ppm}$.

\section{B. Kinetics studies}

The decomposition of $\mathrm{NH}_{3}$ on polycrystalline $\mathrm{Pt}$ has been studied previously in an inert ambient. ${ }^{13,14}$ Nondisso- ciative adsorption of ammonia occurs at temperatures below $160 \mathrm{~K}$ in an essentially nonactivated process. Other authors have found ${ }^{15,16}$ that the reaction for ammonia decomposition on platinum at higher temperatures is complex. Presumably, decomposition of $\mathrm{NH}_{3}$ to $\mathbf{N H}_{x}$ takes place and the reaction rate is determined by the dissociation rate of the $\mathrm{NH}_{x}$ species.

Under the present experimental conditions one can expect $\mathrm{NH}_{3}$ to be partly molecularly adsorbed and partly dissociatively chemisorbed on Pt. The fact that the adsorption signal increases with temperature supports the presence of some thermally activated dissociative chemisorption.

Kinetics studies were carried out by monitoring the capacitance of the device as a function of time and zero bias upon introduction and removal of $\mathrm{N}_{2}$ and $\mathrm{NH}_{3}$ in $\mathrm{N}_{2}$ or in synthetic air. Reaction orders with respect to $\mathrm{NH}_{3}$ were determined by examining the dependence of the initial rate of change of capacitance $(\tan \alpha)$ during transients on ammonia partial pressure at a given temperature (see Fig. 2).

Reaction orders with respect to $\mathrm{NH}_{3}$ have been estimated using different background atmospheres as shown in Fig. 11(a). A reaction order equal to one is calculated from the time evolution of the signal attributed to $\mathrm{NH}_{3}$ adsorption in $\mathrm{N}_{2}$ at $150^{\circ} \mathrm{C}$. When synthetic air is used as carrier gas, the reaction order decreases to 0.5.

The corresponding desorption reaction orders have been calculated from the corresponding data in Fig. 11(a). Desorption was carried out in all cases at $150^{\circ} \mathrm{C}$, zero voltage bias, and $50 \% \mathrm{O}_{2}$ in $\mathrm{N}_{2}$. Under these conditions, the zero-reaction order observed indicates that the desorption process is independent of $\mathrm{NH}_{3}$ concentration, both in $\mathrm{N}_{2}$ or in synthetic air, as can be seen in Fig. 11(a). Desorption of $\mathrm{NH}_{3}$ in $\mathrm{N}_{2}$ occurs faster than in synthetic air.

Examination of the dependence on temperature of the initial rate of change of capacitance during transients for a given gas-phase composition allowed for the determination of the activation energies associated with the process of $\mathrm{NH}_{3}$ or $\mathrm{N}_{2}$ introduction and removal from the $\mathrm{Pt} / \mathrm{GaAs}$ structure.

The activation energy for $\mathrm{NH}_{3}$ adsorption in $\mathrm{N}_{2}$ has been evaluated in the temperature range between 100 and $150^{\circ} \mathrm{C}$ for two concentrations: $970 \mathrm{ppm}$ (the first adsorption process is not observed) and $75 \mathrm{ppm}$ (the first adsorption is observed). From the Arrhenius plot shown in Fig. 11(b), an activation energy of approximately $8 \mathrm{kcal} / \mathrm{mol}$ has been estimated for the higher concentration, attributed only to ammonia adsorption. For the lower concentration, two adsorption ènergies have been calculated. The first adsorption (curve $\mathrm{N}_{2}$ ) gives a value of $15.3 \mathrm{kcal} / \mathrm{mol}$ and the second one (due to $\mathrm{NH}_{3}$ ) gives a $7.5 \mathrm{kcal} / \mathrm{mol}$ value. This latter value is in good agreement with the previously obtained result for the higher $\mathrm{NH}_{3}$ concentration.

Wilf and Dawson ${ }^{12}$ studied the interaction of $\mathrm{N}_{2}$ with polycrystalline $\mathrm{Pt}$ and observed dissociative nitrogen adsorption at room temperature. The rate of dissociation depended only on the time exposure, but not on the $\mathbf{N}_{2}$ gas pressure. The energy necessary to break the dinitrogen 


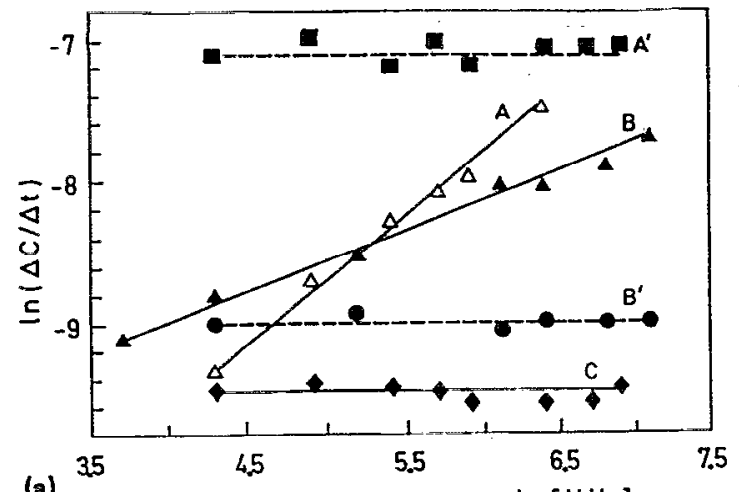

(a)

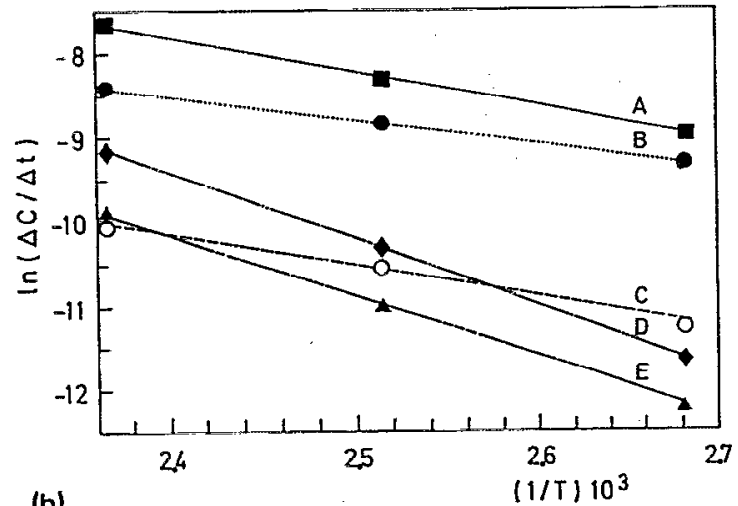

(b)

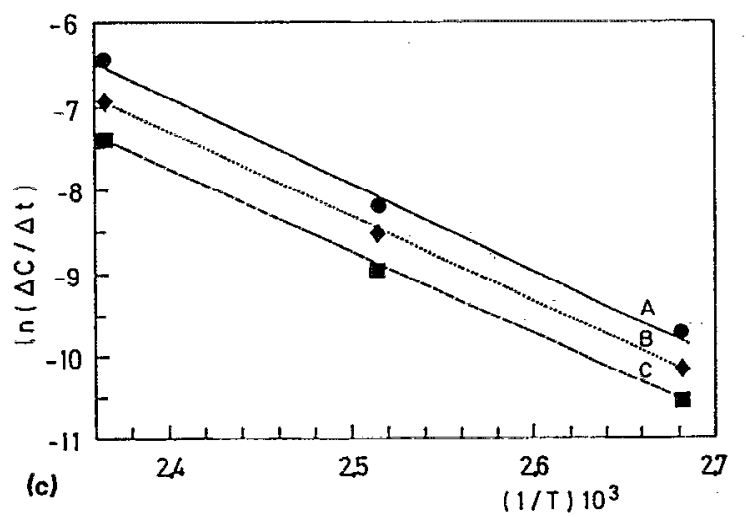

FIG. 11. (a) Dependence of initial signal change $(\Delta C / \Delta t)$ on $\mathrm{NH}_{3}$ partial pressure, at $150^{\circ} \mathrm{C}$ and $O \mathrm{~V}$. (A) adsorption $\mathrm{NH}_{3} / \mathrm{N}_{2}$, reaction order, $n=1$; (B) adsorption $\mathrm{NH}_{3}$ /synthetic air, $n=0.5$; (C) first adsorption observed in $\mathrm{NH}_{3} / \mathrm{N}_{2}, n=0$; $\left(\mathrm{A}^{\prime}\right)$ desorption of (A), $n=0$; ( $\mathrm{B}^{\prime}$ ) desorption of (B) $n=0$. (b) Arrhenius plot for the adsorption of (in the 150-100 ${ }^{\circ} \mathrm{C}$ temperature range): (A) $970 \mathrm{ppm} \mathrm{NH}_{3}$ in $\mathrm{N}_{2}, E_{a}=8 \mathrm{kcal} /$ mol; (B) $34 \mathrm{ppm} \mathrm{NH}$ in synthetic air, $E_{a}=5.6 \mathrm{kcal} / \mathrm{mol}$; (C) $75 \mathrm{ppm}$ $\mathrm{NH}_{3}$ in $\mathrm{N}_{2}, E_{a}=7.5 \mathrm{kcal} / \mathrm{mol}$; (D) $\mathrm{N}_{2}$ gas, $E_{a}=15.8 \mathrm{kcal} / \mathrm{mol}$; (E) first adsorption observed in the adsorption curve of $75 \mathrm{ppm} \mathrm{NH}_{3}$ in $\mathrm{N}_{2}, E_{a}$ $=15.3 \mathrm{kcal} / \mathrm{mol}$. (c) Arrhenius plot for the desorption of (in the 150$100^{\circ} \mathrm{C}$ temperature range): (A) $970 \mathrm{ppm} \mathrm{NH}_{3}$ in $\mathrm{N}_{2}, E_{a}=20.6 \mathrm{kcal} / \mathrm{mol}$; (B) $75 \mathrm{ppm} \mathrm{NH}_{3}$ in $\mathrm{N}_{2}, E_{a}=20.3 \mathrm{kcal} / \mathrm{mol}$; (C) $\mathrm{N}_{2}$ gas only, $E_{a}=19.9$ $\mathrm{kcal} / \mathrm{mol}$.

bond on the surface is easily compensated by the formation of the strong metal-nitrogen bonds. Adsorbed oxygen or sulfur inhibits nitrogen dissociative chemisorption mainly through a blocking of surfaces sites. This is probably the main reason why $\mathrm{N}_{2}$ adsorption is not observed in an oxygen-containing ambient.

Heterogeneous catalysis studies have indicated that the

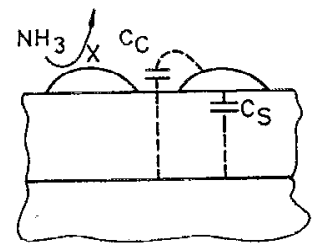

(a)

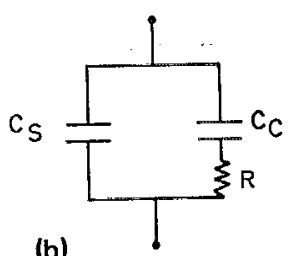

(b)
FIG. 12. (a) Schematic illustration of the proposed mechanism to explain the ammonia sensitivity of devices with porous $\mathrm{Pt}$ film. $C_{s}=$ Schottky diode capacitance, $C_{c}=$ coupling capacitance, and $X=$ intermediate and/ or reaction products of $\mathrm{NH}_{3}$ decomposition. (b) Equivalent electrical circuit of (a).

dissociative adsorption of molecular nitrogen on $\mathrm{Pt}$ is an activated process with an activation energy approximately $16 \mathrm{kcal} / \mathrm{mol}^{13}$ The chemisorption of dissociatively adsorbed $\mathrm{N}_{2}$ was observed to occur above room temperature. The linearly bound $\mathrm{N}_{2}$ molecule is the precursor for dissociation. Dinitrogen is bonded perpendicular to the metal surface through one $\mathbf{N}$ atom. Simultaneously with the dissociation of the $\mathrm{N}_{2}$ bond, a bond between the $\mathbf{N}$ atom directed away from the surface and the metal is formed.

According to this, dissociative chemisorption of nitrogen takes place under the experimental conditions examined. We have been estimated an activation energy of 15.8 $\mathrm{kcal} / \mathrm{mol}$ for nitrogen adsorption, in good agreement with above results, in the temperature range between 100 and $150^{\circ} \mathrm{C}$. This value is similar to that obtained for the first adsorption observed in the $\mathrm{NH}_{3} / \mathrm{N}_{2}$ adsorption process, in good agreement with the above discussion.

The situation is quite different with the presence of oxygen. $\mathrm{Pt}$ is known to be a good oxidation catalyst for $\mathbf{N H}_{3}$, and chemical reactions occur on the Pt surface at temperaturcs below $500 \mathrm{~K}$. The reaction products are: $\mathrm{H}_{2} \mathrm{O}, \mathrm{N}_{2}$, nitric oxide (NO), and/or nitrous oxide $\left(\mathrm{N}_{2} \mathrm{O}\right) .{ }^{17,18} \mathrm{An}$ activation energy of $5.6 \mathrm{kcal} / \mathrm{mol}$ has been estimated for $\mathrm{NH}_{3}$ adsorption in air between 100 and $150^{\circ} \mathrm{C}$ for the adsorption of $34 \mathrm{ppm} \mathrm{NH}_{3}$ in synthetic air from the plot shown in Fig. 11(b). This value of activation energy, $5.6 \mathrm{kcal} / \mathrm{mol}$, compared to $8 \mathrm{kcal} / \mathrm{mol}$ for adsorption in $\mathrm{N}_{2}$ ambient, correlates to the more rapid response achieved in the first case (see Fig. 10). This result is in good agreement with the fact that $\mathbf{N H}_{3}$ adsorption takes place more rapidly in air.

Figure 11(c) shows the activation energy of the desorption processes for the same temperature range studied above. Very similar values have been obtained: $20.6 \mathrm{kcal} /$ mol for the desorption of $970 \mathrm{ppm}$ of $\mathrm{NH}_{3} / \mathrm{N}_{2} ; 20.3 \mathrm{kcal} /$ mol for $75 \mathrm{ppm}$ of $\mathrm{NH}_{3}$ in $\mathrm{N}_{2}$; and $19.9 \mathrm{kcal} / \mathrm{mol}$ for the desorption of $\mathrm{N}_{2}$ gas.

Our experimental data could be explained by means of the model proposed by Lundström and co-workers. ${ }^{5} \mathrm{Ac}-$ cording to this author, ammonia molecules and/or reaction intermediates are capacitively coupled with the semiconductor through pores in the metal film. Based on this model, we propose the operation scheme shown in Fig. 12 for our Schottky barrier device.

$\mathrm{NH}_{3}$ sensors based on a $\mathrm{Pt} / n-\mathrm{GaAs}$ Schottky barrier 
have a simpler design than their Si counterparts, which invariable require an intermediate insulator film to avoid a reaction between the metal and semiconductor.

The detection limit reported for $\mathrm{NH}_{3}$-sensitive MOS and MOSFET devices in air at $150^{\circ} \mathrm{C}$ is about $1 \mathrm{ppm}$ of $\mathrm{NH}_{3}{ }^{3,10}$ It was observed ${ }^{2}$ that in certain cases both the speed of response and magnitude of the $\mathrm{NH}_{3}$-induced signal change during operation of the devices. Aging was found to be necessary for the $\mathrm{NH}_{3}$-sensitive $\mathrm{Pt}$ MOSFET reported by Ross and co-workers ${ }^{3}$ to reduce leakage and to improve device operating characteristics, and could be carried out by heating freshly prepared devices at $200{ }^{\circ} \mathrm{C}$ for $48 \mathrm{~h}$. However, the aging process is reversible and is an operating limitation with these devices. The response time (to $90 \%$ of equilibrium level) for the adsorption of 100 ppm of $\mathrm{NH}_{3}$ in synthetic air was $3 \mathrm{~min}$ and for the recovery time is $10 \mathrm{~min}$, with the total recovery taking about $45 \mathrm{~min}$ at $175^{\circ} \mathrm{C}$.

We obtain a greater detection limit, about $6 \mathrm{ppm}$, determined by our experimental setup; the response time, for the same conditions, is $1 \mathrm{~min}$. It is important to note that neither aging nor signal change during operation have been observed.

\section{CONCLUSIONS}

We have found that $\mathrm{Pt} / \mathrm{GaAs}$ devices with a discontinuous metal film are effective and reliable solid-state chemical sensors for the detection of ammonia gas. Devices operate over a wide temperature range and are sensitive even at room temperature. The diodes recover easily in air at $150^{\circ} \mathrm{C}$. The ammonia sensitivity depends on the metal film microstructure. When the metal film is continuous, ammonia sensitivity disappears. Therefore, the $\mathrm{NH}_{3}$ detection mechanism seems different from the $\mathrm{H}_{2}$ operation mechanism.

The adsorption process of ammonia in nitrogen shows two adsorption curves. The first adsorption has been attributed to $\mathrm{N}_{2}$ gas adsorption. This idea is confirmed by experimental results: pure $\mathrm{N}_{2}$ produces an adsorption curve which correlates with the first adsorption observed. The lowering of the Schottky barrier due to $\mathrm{N}_{2}$ gas adsorption coincides with the one produced by the first adsorption. Furthermore, the estimated activation energy for $\mathbf{N}_{2}$ gas adsorption is similar to one obtained for the first adsorption observed in the $\mathrm{NH}_{3} / \mathrm{N}_{2}$ adsorption process. The nitrogen signal observed appears as an interference in our $\mathrm{NH}_{3}$ response determination, although it is possible to differentiate both signals.

Ammonia adsorption in synthetic air is achieved without $\mathrm{N}_{2}$ interference and with a faster response time than in the $\mathrm{N}_{2}$ atmosphere. It is possible to measure $\mathrm{NH}_{3}$ concentrations above $150 \mathrm{ppm}$ with response times lower than 1 min. In a nitrogen ambient, fast response times ( $\simeq 1 \mathrm{~min})$ are only achieved for concentrations above $600 \mathrm{ppm}$. However, in a $\mathrm{N}_{2}$ ambient signal sensitivity improves. The detection limit obtained with our experimental setup is of the order of $10 \mathrm{ppm}$ of $\mathrm{NH}_{3}$ in nitrogen or in synthetic air.

$\mathrm{NH}_{3}$ gas is partly molecularly adsorbed and partly dissociatively chemisorbed on $\mathbf{P t}$. Adsorption rates vary proportionally to the ammonia concentration in the $\mathrm{N}_{2}$ ambient. An activation energy of $\simeq 8 \mathrm{kcal} / \mathrm{mol}$ is obtained for this process. When synthetic air is used as a carrier gas, the reaction order decreases to 0.5 and an activation energy of $5.6 \mathrm{kcal} / \mathrm{mol}$ is obtained. Therefore, the mechanisms for ammonia adsorption in $\mathrm{N}_{2}$ and in synthetic air are different; different rate-limiting reactions occur on the Pt surface. The process is favored in synthetic air, as can be deduced from the activation energy values. Dissociative chemisorption of nitrogen gas occurs on the Pt surface, with an activation energy of $\simeq 15.8 \mathrm{kcal} / \mathrm{mol}$.

\section{ACKNOWLEDGMENTS}

Thanks are due to Francesc Pérez from Universidad Autónoma de Barcelona for the STM observations. The authors would also like to acknowledge helpful discussions with Dr. P. Tejedor, and the growth team of Centro Nacional de Microelectrónica for growing the epitaxial layers.

${ }^{1}$ I. Lundström, A. Spetz, F. Winquist, U. Ackelid, and H. Sundgren, Sensors and Actuators B 1, 15 (1990).

${ }^{2}$ A. Spetz, M. Armgarth, and I. Lundström, J. Appl. Phys. 64, 1274 (1988).

${ }^{3}$ J. F. Ross, I. Robins and B. C. Webb, Sensors and Actuators 11, 73 (1987).

${ }^{4}$ F. Winquist, A. Spetz, M. Armgarth, C. Nylander, and I. Lundström, Appl. Phys. Lett. 43, 839 (1983).

${ }^{5}$ I. Lundström, M. Armgarth, A. Spetz, and F. Winquist, in Proceedings of the 2nd International Meeting on Chemical Sensors, Bordeaux, 1986, edited by J. L. Aucouturier, J. S. Cauhapé, M. Destriau, P. Hagenmuller, C. Lucat, F. Ménil, J. Portier, and J. Salardenne (Bordeaux Chemical Sensors, Talence, France, 1986), p. 387.

${ }^{6}$ P. F. Ruths, S. Ashok, S. J. Fonash, and J. M. Ruths, IEEE Trans. Flectron Devices ED-28, 1003 (1981).

${ }^{7}$ L. M. Lechuga, A. Calle, D. Golmayo, P. Tejedor, and F. Briones, J. Electrochem. Soc. 138, 159 (1991).

${ }_{8}^{8}$ I. Lundström, Sensors and Actuators 1, 403 (1981).

${ }^{9}$ T. L. Poteat, B. Lalevic, B. Kuliyev, M. Yousuf, and M. Chen, J. Electron. Mater. 12, 181 (1983).

${ }^{10}$ A. Spetz, M. Armgarth, and I. Lundström, Sensors and Actuators 11, 349 (1987).

${ }^{11}$ L. L. Kazmerski and D. M. Racine, J. Appl. Phys. 46, 791 (1975).

${ }^{12} \mathrm{M}$. Wilf and P. T. Dawson, Surf. Sci. 60, 561 (1976).

${ }^{13}$ J. J. Vajo, W. Tsai, and W. H. Weinberg, J. Phys. Chem. 89, 3243 (1985).

${ }^{14}$ M. Grunze, in The Chernical Physics of Solid Surfaces and Heterogeneous Catalysis, edited by D. A. King and D. P. Woodruff (Elsevier, Amsterdam, 1982), Vol. 4, p. 143.

${ }^{15}$ J. L. Gland and E. B. Kollin, J. Vac. Sci. Technol. 18, 604 (1981).

${ }^{16}$ B. A. Sexton and G. E. Mitchell, Surf. Sci. 99, 523 (1980).

${ }^{17}$ T. Pignet and L. D. Schmidt, J. Catal. 40, 212 (1975).

${ }^{18}$ J. L. Gland and J. N. Korchak, J. Catal. 53, 9 (1978). 